\title{
Thea Astley Lecture 2007 Byron Bay Writers Festival
}

\author{
Nicolas Rothwell
}

\author{
James Cook University
}

Let me thank the festival's organisers for inviting me to give this lecture in recollection of Thea Astley, a writer strongly linked to the country of far north Queensland and the tropical Australia that I study and frequent and love.

My title already gives away not just the assumptions behind my choice of subject, but also my starting point - and since this is the briefest of talks, no more than a late afternoon amusement, a half-hour of verbal travel, let me plunge strait in to the landscape: what it is, how we see it, and invent it, and move through it with our eyes and words. I would like to make a few forays, to advance tentatively, on a set of related fronts, to explore a realm that seems at once smooth and continuous. I hope to spread before you a different form of country, and to peer into the cracks and fissures in our version of pastoral: though looking too deep into cracks and caverns can be hazardous, as readers of fairy-tales and travellers in the deep Outback know.

Landscape, the word, and the thought, like most of present-day Australia's conceptual and descriptive vocabulary, derives from Europe, and legions of scholars have spent the past generation teasing out the difficulties in that adaptation of ideas. Even in the European Middle Ages, when the word and thought of landscape came into view, it was a constructed, delimited thing: a margin, a frontier domain. You could oppose landscape to wilderness, or forest, just as much as you could oppose it to town. Landscape, in fact, comes to English in the 16th century, through the Dutch, to denote an administered space, a region occupied by man - and, in the Dutch context, that meant a stretch of country tamed, dammed, regulated, made safe from the vagaries of flood and storm. Landscapes were already closer to culture than nature, though they were the emblem, of course, of the natural order. What lay beyond landscape: that was the savage, the unknown: new countries, the far corners of the world. There are evolutionary biologists who believe the strong pattern of landscape preference shown by Europeans - a fondness for open, lightly wooded countryside, with hills, and views, and bodies of fresh, flowing water - comes from our distant past, our days of growth in Africa, when this would have been the logical and most advantageous space for a proto- 
human hunting tribe. Aesthetics as derived from survival imperatives: it is the just-so story that we, in an explaining age, most need. But the European landscapes which lie embedded in our image-memories and the information channels of our society were certainly works of art, developed and perfected: the stone-walled fields of England, the terroirs of France, the vineyards and olive groves that clustered tightly round Mediterranean shorelines: the artifice of such country is clear: less plain, though, is the landscape history of the German heartland. I was somewhat surprised, early this year, to discover, in the pages of a fascinating study, that the quasi-entirety of the Rhineland basin, which I looked out at a great deal during my schooldays, and took as the purest nature, has been changed, and shaped, and regulated over the course of the past 250 years, so that the core landscape of Germanic identity is in some part a sentimental, confected thing.

It is only, though, when we get to Australia that this sequence of invention and projection becomes truly vertiginous, and takes on the quality of multiple reflection we might associate with a rather overdone post-modern narrative. As is very well known, the first explorers, when they began their probes and feints through the bush round Sydney, were delighted by what they found: even on the flanks of the Blue Mountains, and beyond, along the coasts north and south, they came across great swathes of seeming parkland: grassy meadows, interspersed with tall, majestic, well-spaced trees. They imagined they were in the depths of some nobleman's estate - and in a sense they were, for that landscape was very likely the product of an elaborate system of patchwork burning undertaken by its Aboriginal inhabitants. When the settlers reached beyond the dividing range, and its rain shadow, things turned very quiet: and it seems clear that before the onset of colonial times much of the deep bush was only sparsely filled with obvious signs of life. Between the great, slow-running river channels, there was little trace of kangaroos in motion, or birds in flight. That country the western division of NSW - has been vastly changed, indeed quite re-engineered, by the creation of dams and water-points, and the introduction of cattle, creatures which, within the space of two decades, stripped much of the topsoil from the ground. And yet that terrain is not quite in the ordered realm of landscape, it still preserves something of its mournful, threatening character, and I have always felt the most sombre part of the Australian inland is to be found, not in the harsh deserts and the salt-lake regions of the far north-west, but precisely in the Corner Country, that flat, parched plain of mulga, filled with oxbox patterns in the sand - the region where the first surveyors dreamed they might find an inland sea. 
And what did they find instead, as they pushed into the veiled heart of the continent? Were they in landscape, or country, and where did the one stop, and the other begin?

I should like, at this point, to read out a passage written by the first European to penetrate into the geographic centre of Australia, the explorer Charles Sturt, who was a romantic intellectual, a self-dramatising writer of the first rank, a seeker after the sublime in nature, and a distinctly dreamy kind of expedition leader: he had been a near-contemporary of Lord Byron in the classrooms of Harrow School - and I am a little crestfallen that this does not give us a rhyme with Byron Bay, which was named not for the poet but for the less appealing British vice-admiral, John Byron, better known as 'Foul-Weather Jack' because of his frequent ill-fortune with the winds and squalls at sea. Nor is the romantic sense of literature in landscape well served by Port Keats, close to my home in Darwin, which I had always assumed was named after the consumption-afflicted poet, although its name was in fact bestowed by a passing marine explorer, and pays tribute to yet another British vice-admiral. The French had a more enlightened approach, and felt no compunction in naming features of the north Australian landscape they surveyed after Racine, Moliere, Fenelon and Voltaire and I wonder what they would have made of the dunefields of the Simpson desert, as Charles Sturt came upon them, at the point of his expedition's furthest passage, on September 7th, 1845, far up the dry watercourse of Eyre Creek, when he climbed a tall dune, which seemed to him like a still wave on a blazing, immobile sea.

"Ascending one of the sand ridges I saw a numberless succession of these terrific objects rising above each other to the east and west of me. Northwards they ran away before me for more than 15 miles, with the most undeviating straightness, as if those masses had been thrown up with the plumb and rule. How much further they went with the same undeviating regularity God only knows, but I find it utterly impossible to describe the appearance of the country. The ridges were covered with spinifex but only to a certain height. Their summits and about ten feet down either side were perfectly bare, and the hue of vegetation and of barrenness were as strongly marked as the limits of perpetual snow on the sides of the Andes. There was a species of mesembryanthemum that happened to be in blossom and so thickly does it bloom that it gave the ground its own purple and sulphureous tint between long lines of fiery red, whilst the valleys were occupied by dark masses of acacia trees. The scene was awfully fearful: a kind of dread came over me as I gazed upon it. It looked like the entrance into Hell." 
This is a passage from Sturt's relatively little-known letter-journal, an epistolary diary he wrote up for his wife, and his beloved children, all of whom were, like Sturt himself, individuals of great beauty and rather nervous sensibility. Sturt is describing a stretch of desert which I know well, and which lies not too far away from where the township of Birdsville now stands. It is an excellent description: that is one face of the eastern desert, and I have had just such thoughts and feelings while standing on the dune-crests above Eyre Creek, looking into the void. But it is also a very self-conscious and bravura piece of landscape writing, though it is written at the limits of the landscape, where the capacity to see and feel run out, and it describes a piece of land Sturt thought of as the purest wilderness.

Landscape - writing it, seeing it, framing it - has always been a problem in the busy fields of literature, and a quick look at what Sturt has done, and what we could see in almost any other such extended "purple passage," will reveal the disquieting truth: country, in its unalloyed form, is somewhat dull. It has a tendency to be monotonous, and boring, and hard to catch in words. To be plain about it, landscape writing requires a good deal of tradecraft, otherwise it quickly goes dead. Even the most sublime writers of the Australian landscape know this, and populate their country with presences and figures of speech and flights of imagination: as does Sturt in the several accounts he left behind him of this decisive moment in his exploring life, when he abandoned his quest for the Centre, and the inland, and returned to Adelaide, and the travails and misfortunes which he sensed ahead. In just a handful of sentences, Sturt launches into extended metaphor, brief tribute to the divine creator, botanical analysis, precise geographic comparison, raw emotional response and, as his final flourish, an invocation of the maw of hell. Even the most articulate and resolved of contemporary landscape writers, such as the peerless Eric Rolls, who understands the landscapes of western NSW with a master's encyclopaedic eye, make sure to people the country with stories, with memories, with anecdotes and episodes, until quiet, empty-seeming land is covered, like a morning sand-dune, with a reduplicating set of literary tracks.

In my own attempts to describe the inland, I have found it always prudent to have diversions or parallel channels running in the narrative: to be engaged in the routines of driving, while one tells one's story, or to be in conversation, or remembering, or dreaming with one's eyes open. For, as the writers here among you know well, it takes only a sentence or two of unrelieved landscape description for country to lose its charm. This, of course, is just what one finds in life. One is only very rarely present to a place: fully present, without the 
engagement of the constantly modulating pressure of the self. I suspect the recreation or the evocation of such total presence belongs more in the domain of religious insight, or meditative discipline, than in the world of literary art, which I think of as the written mirror of probing, active, life-filled consciousness, a kind of mimic-system or proof-text of the wave of thought. And thought enters into any landscape. If you travel into a place you don't know, your mind is constantly drawing pictures and connections for you as you advance; and if you go through country you know well, it opens up before you like a book.

In just this way, if I drive one of the tracks in the western desert that means the most to me, the road, always thick with corrugations, that runs from the Olgas towards Kaltukutjara, Docker River, across sand-dune country thick with bloodwoods and grevilleas, until the lovely groves of desert oaks come into view, and the sharp, deep mass of the Blood Range, and the curves of the Musgraves, I am only rarely seeing the bush itself: I might remember the strange events that have befallen me along that road, where one is constantly being stopped by desert people whose cars are in states of profound collapse: I might reach the sharp bend where I almost crashed into two graders pulled up alongside each other in the middle of a violent rainstorm, or pass a faint turn-off I took once on the hunt for side-tracks to Lasseter's Cave; I might glimpse a bird on the wing, and think back to when I saw a black falcon near there, flashing by, or slow down for the bottleneck beside the Docker camp-site, and see a pair of dingos, and wonder if they might be the children of the dingos I stopped to feed once, and gave a whole plastic container of Woolworths ANZAC biscuits because they seemed so thin and mangy - but then what dingo ever looks in good condition?

And as I pass these fragments through my mind, even now, I see the country: I am there again, I have charted and shaped and mapped it in my thoughts - the mental pictures act as a mnemonic, they bring back the past and make it narrative - and this, of course, is just what writers in the landscape always do, whether consciously or unconsciously: they are reverseengineering the mind, and making a pathway for the reader's imagination to tread. Hence the tie, I am tempted almost to say the conspiracy, between words and memory of landscape: they almost need each other to survive, as map and symbols go together and take life only from their precise and subtle marriage.

Nor is this a purely western, literary business. I have travelled those same desert roads a great deal with Ngaanyatjarra Aboriginal friends of mine, and the process is rather similar, though it stems from knowledge and familiarity at a far deeper level: Look, that's the turn-off to 
mission flats, where the wild men used to come with spears in early days - and over there, near those trees, that way, there's a Seven Sisters site, and that's where we shot those two bush turkeys, once, earlier this year, maybe, and that's where Layla had the fight with her husband, and: slow down - here's the bend where linguist Kazuko rolled her Troop-Carrier, and we were all in the back; and just up ahead, that's the spot where we all camped beside the honey grevilleas, right there - and soon, endlessly, a mesh of story and memory binds the country up. And so it goes, across the continent: there are stories everywhere, being spun, and being recollected: country is always on the way to becoming landscape in our minds: and equally, stories are dying, a whole language of stories has been dying - and I often wonder whether their trace stays in the landscape for a long time afterwards, and whether the halfvanished presence of those old stories keeps the country veiled from those coming into it.

Let me, at this point, divert, a moment, from the track I have been following, which has led us, in slightly mazy fashion, from the idea of the Australian landscape, and the inland, right back to the mind's structure, and to ways of catching and describing country in thought and words.

When romantic ideas of landscape and imagination were first coming into focus, about the time of Australia's colonisation and settlement, the science of mind was in its infancy: religious and philosophical inquiry set the tone for much thinking about thought: and the analytic way of proceeding is still dominant, though it often advances masked by a bodyguard of sentimental outriders. But the past few decades have seen physiologists and students of consciousness open up new, still speculative avenues. This is not my field: although I preserve a strong admiration for the romantic poet Shelley, the last European high intellectual who actually aimed at knowing everything: all the latest information and research in politics and aesthetics, in economics and in science. For a long time, I believed that science held vital lessons for art and for literature, and I like to trace the parallels, whether coincidental or adopted, between these fields even now. Research into the mind has always held a certain glamour for me: enough, at any rate, to lead me to keep a vague eye on the field, and watch its progress: or perhaps I should say its disintegration into new sets of first principles. At a very high level of generalisation, we can speak of a fresh picture emerging of thought, and consciousness, and perception. In everything we sense, there seems to be a slight mismatch between what we pick up and when we are aware we are sensing it. Sometimes, our movements precede, infinitesimally, our conscious decision to make a movement. If a 
patient with his visual centres damaged by a certain kind of brain injury is shown an object in his field of vision, he appears to be able to sense it through "blindsight" without knowing that he sees it. Above all, when we look about us, what we resolve and detect with accuracy is only the central part of the field of vision: the brain, like a constant improviser, is filling in the rest of the detail. These are clearly findings with the utmost relevance for visual artists, and for writers, too, given the skein of entanglement that ties together sight and word and thought and text. I would like, at this stage, simply to set out a few markers along our way:

Landscape, in the terms that information scientists once used to favour, could be called digital, while desert, wilderness or bush is analog. Landscape is differentiated, delimited, bordered, denoted; while bush is seen as continuous, without clear frontiers, so that its tones and hues vary in the most subtle fashion: it has yet to be brought into the province of western man. And hence, of course, the difficulty of writing about it, and using the tradecraft we have for landscape, where our linguistic devices seem to me remarkably similar to the "fill-in" devices the brain supplies to us in its constant perceptual tasks. We make up the landscape as we go - and this is a circumstance that holds the most alarming lessons for our complaisant, reflexive embrace of realism as a standard of artistic measure: and often it seems to me, in my own journeys into the Australian bush, that this is the secret message it is murmuring; that this is the content of the wind blowing through the leaf-veils of the desert oaks, and between the branches of the bloodwood trees. It would be very tempting, at this stage, to veer off, and pursue the obvious point that traditional Aboriginal story-making, and world-making, from what I can gather of it, looks very much like a triumphantly continuous way of conceiving country - but we are always in danger, in such assessments, of building a caricature of strange, distinct practices upon a world that seems to me already cruelly and pruriently overstudied.

Let me turn, instead, to an even more radical thought. The wilderness, the inland, the desert, the Centre: what is it? Primeval, surely? The ambiguous work of nature, and climate, and time: and certainly we know that the sands of the desert are in large part the ground-down remains of ironstone and sandstone ranges, full of the red oxide used in women's make-up, so that one is stained an elegant blush-pink whenever one touches damp soil from the heartland. The salt-lakes marked on the map are not really lakes at all, but memories of lakes, zero points of dry watersheds, fed only by saline flows down ancient, unchanging river channels. But the deserts, though they mark nature's bleak victory over man, may also be, in some part, 
of artificial manufacture. And at this point I should introduce to the stage of this journey my friend Peter Latz, the free-thinking botanist, the Casanova of the Centre, an individual whose knowledge of bush trees and plants is very likely unmatched. Latz is tall, and rake-thin, and he is most comfortable alone, or in the company of women, or in the deep desert, and all these traits are bars to the development of our association: but I have spent enough time with him to have a grasp of his theories about the landscape of the Centre - a landscape he has known ever since he was brought up among the Aranda of Hermannsburg mission outside Alice Springs, whose language he speaks as his own. Latz's ideas are hinted at in the everpopular "Bushfires and Bush Tucker," the best-selling title on the backlist of the IAD Press: a guide to the medicinal and nutritional properties of desert plants. Those ideas find a fuller expression in Latz's rather beautifully titled masterpiece, "A Flaming Desert," which, typically, after endless unheroic shilly-shallyings by east and west coast publishers, has yet to find its way into print. Many of its ideas have been voiced, in less disquieting form, by scientists who are much better-known. You can find a little trace of thought with Latzian flavour in Tim Flannery's first big success, "The Future Eaters," when the present Australian of the Year turns to firestick farming, the patchwork burning system whose signs were noticed by the first NSW settlers colonists, and whose methods were pieced together by the Canberra archaeologist Rhys Jones. Latz's ideas go far beyond. He believes that much of the far western desert - the world beyond landscape - bears the mark of man. His argument, in very stripped-down terms, is that man's entry to Australia heightened natural burning, and changed the balance of the vegetation: so much so that deserts, spinifex and desert oaks, still spreading, are the result, and the human hand has helped shape the deepest reaches of the Gibson and Great Sandy deserts. For spinifex, like the desert oak, is a plant that thrives on fire, and needs it to spread, and spreads through it by destroying the habitats of rival, firesensitive plants. What did the Centre look like before the change? Patches of remnant vegetation can still be found, here and there, even around Alice Springs: old dry forests of coolibahs and twisting tendril-vines, with strikingly unusual populations of animals and birds. Some indigenous intellectuals and their self-appointed allies don't much like this version of continental settlement, which fits ill with the beatific vision of indigenous man poised in tranquil balance with the land. Latz, though, regards his theory as one that pays tribute to the power of the first incoming fire-users, who shaped, by their actions, a world - and then adapted to what they shaped. And perhaps the truth may lie only in part with such ideas - and I cite this theory as much in admiration of its design as in conviction that its catastrophism explains every detail of the inland - but there is a intriguing corroborative web of shards and 
fragments to support the Latzian view: a view that sees the desert, that ultimate wilderness, that zone beyond the western landscape, as being itself a distant consequence of thoughts and words. Latz would make the north-west the point of radiative origin for the flames that march across the desert - and the Pilbara coastline is also a natural landing-point for incomers in the far past from the archipelagic regions closest to Australia: there are, as we now know, many tell-tale depictions of ocean-going vessels in the ancient rock art of the north-west. Spinifex itself seems to radiate out from an area in the Pilbara, around the national park at Millstream, and so do western desert languages - and I cannot forebear entirely from mentioning that desert magic healers regard the nearby area around present-day Newman as the originating source of their powers, a region they travel to, in dream or fact, whenever they feel most in need of replenishment.

Over the past month or so, while I was collecting together and sifting through these thoughts on landscape and on art, I was, as it happens, taking part in a scientific journey through the Simpson - the same compact, forbidding sand-ridge desert Sturt encountered in his explorations more than 150 years ago. Today, as the 4WD enthusiasts and expeditioners among you will know, the Simpson, for all its bleak austerity, is not exactly trackless: from the Birdsville side, you can follow broad desert roads and cuts and seismic lines, and make your way, in a few adventurous days, deep into remote country - and even complete a crossing of 400 kilometers, on the well-worn tracks between Eyre Creek and Dalhousie Springs. I though, together with my photographer friend Peter Eve, and a group of researchers, was on foot, walking beside a camel-train, in a much less fashionable corner of the Simpson: the southern fringe, well below Poeppel Corner, the point, marked out by a saltlake, where the boundaries of South Australia, Queensland and the Territory meet. This stretch of the desert has pale, whitish dunes, and a subtle, shifting temperament: it is traversed by the wide, undulating sand-bed of the Kallakoopah Creek, and, when rain comes down from the channel country, it turns into an ephemeral saline wetland, full of birds and flowers. The night-time shadows of the coolibah trees, the sound of the grass-wrens, the rasp of the sand on one's skin - how I wish that I could conjure them up for you, or even that photographs could bring them back for outside eyes, but the sense of being in such places is bound up with the going, and the consciousness that one's time there is dying once it starts. I found walking, rather than driving at speed, and walking beside animals, transformed much about my sense of the country - it read differently: and walking in company, even if we were mostly silent, was, at times, a sharp intensifier of the experience of place. The Simpson feels, 
to those who pass through it, like a space of nature, and in fact it is not terrain that falls inside the scope of Latzian theory - it has not been wholly fire-changed: at least not yet. It is very much a maverick among Australian deserts: the dunes, with their metronomic north-northwest alignment, are bizarrely regular; it is less vegetation-covered than the great deserts of the west, it borders the "adamantine" plain of gibbers once known as Sturt's stony desert; and it has a different spirit. But at its western fringe, south of Old Andado station, there are marauding stands of desert oak, which Latz would tell you are the first invaders - and spinifex, the lobed variety, Triodia Basedowii, is present there too, though it is very striking that beyond this advancing shock-front there is almost no spinifex in the centre and the southern areas of the desert. Was our expedition, the sublimely named Arid Rivers Research Expedition 2007, engaged in a passage through wilderness, or landscape: were we in nature, or culture, or in a threshold world where both orders were entangled with each other, or in some new hybrid born of the two? The southern Simpson is under study, and on the way to being well-described: indeed our trip seemed to have some loose tie with the National Land and Water Audit, a program of the Natural Heritage Trust - and this explained the declared and near-obsessive interest of my scientific fellow-travellers in unearthing signs of threatened fauna, such as the Greater Long-Eared Bat, and the Dusky Hopping-Mouse.

Scientists have also done much to make the Simpson known as an emotional space: the desert was crossed in 1939 by a party under the leadership of the protean geologist and Antarctic explorer Cecil Madigan; its fringes were much visited during the same fateful period by the biologist Francis Ratcliffe, whose literary masterpiece, "Flying Fox and Drifting Sand," evokes the river systems of the Cooper and Diamantina, and their moods and presences, "which are not friendly to man." Both Madigan and Ratcliffe are heroes of mine, and both of them, I feel, have left traces of themselves in that braided, algebraic desert - but over time I have come to see a previous layer of attention in the wind-swept sand.

It was widely assumed for much of the past century that Aboriginal people spent little time in the Simpson, so great were its rigours. The Wangkanguru, who lived on its southern fringes, and were the last Aboriginal people in the Lake Eyre Basin to encounter Europeans, found themselves, in the late 19th Century, increasingly drawn in to the missions, with their tempting supplies of food: the last of their number left the Simpson in 1900, and by the mid70s only three old men who were desert-born survived: all have now died, and the memorystore of the Wangkanguru is kept by their descendants, many of whom live in distant Port 
Augusta. Only recently have archaeologists and anthropologists begun to decode the story of the desert's Aboriginal past, which lies in fragments, and is hard to read, and may reach back some 2,700 years - to the age when the Homeric epics were being set down in their final form. This is the time horizon of Aboriginal settlement in the deep sand-dune country. The usual scatter of flints and stone flakes and hand axes one encounters everywhere across the inland can be found through stretches of the desert's fringe - but the most intriguing features of the Simpson's human landscape are its Mikiris - or native wells. These are in fact soaks, lying between the dunes, and reached by deep-dug, carefully maintained shafts. This is the pattern in the western desert too, and I have often been astonished by the capacity of bush people to navigate from well to well across vast stretches of hard land.

The indefatigable surveying explorer, David Lindsay, was able to cross the southern Simpson with a Wangkanguru man in 1886, using these wells as supply points, and recording their names - and the sites of several of them have been found again: they are associated with life in the landscape: grasshoppers, corkwoods, acacias. Marapardi, pirlakaya, perlani, walpurkanha, pulapurdu - how soft and delightful their names are: this is the half-forgotten vocabulary of the desert. It was pulled back from the brink of oblivion by a remarkable linguist and scholar of Sanskrit, Luise Hercus, who worked with one of the last desert-born Wangkanguru, Mick Mclean Irinjili, to record the country's language, and the patterns of its Aboriginal habitation before the final exodus. Even now, Mikiri wells are being found, and the secret of their precise location stays well kept by western science. My historian friend Philip Jones once described to me, in extremely guarded terms, a helicopter trip he made, some years ago, to a Mikiri site in the deep Simpson, which had been preserved intact: there were the sweet signs of familial habitation: digging sticks, carved objects, wooden coolamons, chipped, worked stones. All had been left there long ago, as if their owners fully expected to use them again, in some future close ahead. Coming across such sites in the deep bush is a disconcerting affair: it is hard to avoid a sense of trespass that, in the remainder of the country, has been largely washed away - but doubtless in time all the remaining undiscovered traces of past cultures will have been found, and catalogued, and their meanings, and the fields of their memories, will slowly change.

These are some of my ideas about the landscape of the Centre and the North: country both harsh, and hard to survive in, and filled with a beauty and a dignity that give depth to life. I began by exploring some of the paradoxes of nature, and man's place in the order of the bush, 
and the way we create our languages of country almost to suit our needs and our desires: the way we make landscape, with our brisk environmental manipulations; with our words that imitate, as they must, the mind's pulse. The country, though, is not just a made-up thing, constructed, alive with our dreams. It is not just the screen from which we draw our words and thoughts, which we have already busily poured into it. There is a landscape behind the landscape, which we are always reaching for, and seeking with our eyes and hearts. It is the landscape that is always there, and always receding, and that seems especially well evoked by the Aboriginal conceptual frame of the Tjukurrpa, which is both the flash of the present moment and the echo, far off, from primary, long-vanished events. Can today's Australians inhabit such landscape? Can we feel at home there? When you find yourself in a pale dunefield at sunset, with the sky blush pink and deepest indigo, or when you look out from the crest of an inland mesa at the clouds in their indifferent race across the sky, such questions tend to dissolve, and patterns and thought-chains separate from man's deliberate kingdom take hold: and I have always felt, at such moments, on the verge of dissolution close to death, as much as on the threshold of new revelations in the march of life - and rather than imposing my will on country, or on landscape, and prolonging the dictatorship of control and consciousness, I am overwhelmed - I am a creature of new rhythm, and the desert, and the inland, are writing me. 